\title{
Immunoglobulin Therapy
}

National Cancer Institute

\section{Source}

National Cancer Institute. Immunoglobulin Therapy. NCI Thesaurus. Code C62710.

The use of immunoglobulins in the treatment of any disease or disorder. 